\title{
O Ato Administrativo de Concessão de Registro de Medicamentos na Agência NaCional de VigilânCIa SANITÁria ${ }^{(*)}$
}

\author{
Denise Lyra ${ }^{(* *)}$ \\ Maria Célia Delduque (***) $^{(* *)}$
}

\section{RESUMO}

O medicamento, por ser um produto especial, tem que apresentar-se eficaz, seguro e com qualidade, para que no seu consumo estejam minimizados os possíveis riscos à saúde da população, o que é verificado através da análise técnica rigorosa das petições de registro. A concessão de registro de medicamentos é exposta neste trabalho como o ato administrativo que permite o direito à fabricação para a sua posterior entrada no mercado. $\mathrm{O}$ estudo ainda discute que apesar do ato administrativo do registro de medicamentos ser caracterizado como ato vinculado, algumas decisões dos técnicos que analisam registros são efetuadas com base na discricionariedade técnica, fazendo com que a Administração deva estar bem fundamentada tecnicamente para tomar decisões corretas, uma vez que a forma de proceder a análise não é descrita na legislação.

(*) Trabalho originalmente apresentado no formato de monografia para o Programa de Pós-graduação em Saúde Coletiva da Fundação Oswaldo Cruz, Diretoria Regional de Brasília, como requisito para a obtenção do título de Especialista em Direito Sanitário, em 2007. Trabalho igualmente apresentado ao 5ํㅡㄹ Congresso Riopharma de Ciências Farmacêuticas, em setembro de 2007, e publicado nos respectivos Anais.

$\left.{ }^{(* *}\right)$ Farmacêutica industrial, especialista em Direito Sanitário pela Fundação Oswaldo Cruz, servidora Especialista em Regulação e Vigilância Sanitária da Agência Nacional de Vigilância Sanitária. Email: denise.lyra@anvisa.gov.br.

$\left.{ }^{(* *}\right)$ Advogada, especialista em Direito Sanitário pela Universidade de São Paulo, mestre em Planejamento e Gestão Ambiental pela Universidade Católica de Brasília, doutoranda em Saúde Pública pela Universidade de São Paulo, pesquisadora da Fundação Oswaldo Cruz - Brasília. Email: <delduque@fiocruz.br>. Recebido em 12.1.09. Aprovado em 13.4.09. 


\title{
Palavras-chave
}

Ato administrativo; Discricionariedade Técnica; Registro de Medicamentos; Vigilância Sanitária.

\begin{abstract}
Drugs as a special product have to be efficient, safe and present good quality, with the purpose of minimizing the possible risks to the population health which could be verified through a rigorous technical analysis of the register requirements. The aim of this study is to expose medicine registration grant as an administrative act which allows manufacturing rights and the launch of products into the market. Despite being considered an entailed act, some technicians decisions about medicine registration are based on technical discretionary, requiring a well-based technical foundation of the part of the public administration to ensure correct decisions, considering that the procedures are not totally detailed by legislation.
\end{abstract}

\section{Keywords}

Administrative Act; Drugs Registration; Health Surveillance; Technical Discretionary.

\section{INTRODUÇÃO}

A utilização de medicamentos é uma das formas amplamente utilizadas de se recuperar a saúde. Os medicamentos são produtos a serem regulados pela Vigilância Sanitária, pois, embora tenham finalidade de recuperação e promoção da saúde, podem ser agentes causadores de danos. Assim, antes de sua entrada no mercado é necessária uma avaliação da qualidade, eficácia e segurança por meio do processo de registro pelo órgão competente do Ministério da Saúde, atualmente a Agência Nacional de Vigilância Sanitária (ANVISA).

Tendo em vista a caracterização do ato administrativo na concessão de registro do medicamento, neste estudo discute-se o grau de liberdade na prática do ato, ou seja, a aplicação dos conceitos de ato vinculado e ato discricionário, no âmbito do registro de medicamentos. Considerou-se oportuna a abordagem dos temas: a importância da análise técnica rigorosa das petições de registro de medicamento; os princípios da administração pública; a conceituação de processo e procedimento administrativo; os elementos do ato administrativo; e a questão da discricionariedade técnica. 
Este trabalho é originário da monografia apresentada ao Programa de Pós-graduação em Saúde Coletiva da Fundação Oswaldo Cruz, Diretoria Regional de Brasília, como requisito parcial para obtenção do título de Especialista em Direito Sanitário, em 2007. Portanto, um maior detalhamento das questões abordadas neste artigo encontra-se na referência original. ${ }^{(1)}$

\section{DIREITO À SAÚDE, VIGILÂNCIA SANITÁRIA E MEDICAMENTOS}

A saúde é designada como um bem jurídico, um direito fundamental social na $\mathrm{CF} / 88$, pois que se entende a dignidade como um dos fundamentos do Estado. Assim, conforme definição em seu art. 196:

A saúde é direito de todos e dever do Estado, garantido mediante políticas sociais e econômicas que visem à redução do risco de doença e de outros agravos e ao acesso universal e igualitário às ações e serviços para sua promoção, proteção e recuperação. ${ }^{(2)}$

A Carta Magna, como meio de concretizar o direito à saúde, também criou o Sistema Único de Saúde (SUS) e para regulamentar sua estrutura e funcionamento foi aprovada a Lei Orgânica da Saúde, Lei n. 8.080/90, que dispõe sobre as condições para a promoção, proteção e recuperação da saúde, a organização e o funcionamento dos serviços correspondentes. Como citado na CF/88 "a redução de risco de doença e de outros agravos" é um dos objetivos presentes no Direito à Saúde dos cidadãos brasileiros, o que envolve o conceito de vigilância sanitária disposto na Lei supracitada, em seu art. $6^{\circ}, \S 1^{\circ}$ :

Um conjunto de ações capaz de eliminar, diminuir ou prevenir riscos à saúde e de intervir nos problemas sanitários decorrentes do meio ambiente, da produção e circulação de bens e da prestação de serviços de interesse da saúde.(3)

O medicamento, embora tendo a finalidade de recuperação e promoção da saúde, sendo definido pela Lei n. 5.991/73(4) — que dispõe sobre o controle sanitário do comércio de drogas, medicamentos, insumos farmacêuticos e correlatos - e por seu Decreto regulamentador, n. 74.170/74(5), como "produto farmacêutico, tecnicamente obtido ou elaborado, com finali-

(1) SANTOS, Denise Lyra dos. O ato administrativo de concessão de registro de medicamentos na agência nacional de vigilância sanitária. Brasília: Direb; Fiocruz, 2007. p. 39. Monografia (Especialização) - Direito Sanitário, Brasília, 2007.

(2)Constituição da República Federativa do Brasil, 1988, artigo 196.

(3) BRASIL. Lei n. 8.080, de 19 de setembro de 1990. Artigo 6ํㅗ $\S 1^{\circ}$ - Disponível em: <http:// www.anvisa.gov.br/e-legis/>.

(4) Id. Lei n. 5.991, de 17 de dezembro de 1973. Disponível em: <http://www.anvisa.gov.br/e-legis/>.

(5) Id. Decreto n. 74.170, de 10 de junho de 1974. Disponível em: <http://www.anvisa.gov.br/e-legis/>. 
dade profilática, curativa, paliativa ou para fins de diagnóstico", também pode ser agente causador de danos aos indivíduos, em razão, por exemplo, de efeitos adversos ou uso irracional.

O registro de medicamentos é para Said ${ }^{(6)}$ uma das ações mais importantes do controle sanitário e da regulação, pois permite ao órgão regulador ter o conhecimento de quais medicamentos estão no mercado, tendo a finalidade de garantir produtos com qualidade, eficácia e segurança, além de ser um pilar para a execução de uma série de ações de vigilância sanitária, uma vez que é por meio dele que o medicamento pode ser disponibilizado para o consumo da população. Sua instituição como ato de órgão governamental é relacionada a acontecimentos que causaram danos à saúde e até a morte. Como exemplos destacam-se os casos do medicamento elixir de sulfanilamida, em 1937, que, por conter em sua formulação o dietilenoglicol, substância tóxica, causou a morte de centenas de pessoas em poucos dias; e na década de 60 , em razão do uso do medicamento talidomida, indicado para náuseas e vômitos em gestantes, decorreram milhares de casos de focomelia em recém-nascidos. Descreve-se, ainda, que, na área de medicamentos, são instrumentos importantes para a concessão de registro sanitário, o cumprimento das Boas Práticas de Fabricação (BPF)(7) pelas empresas solicitantes, verificada por meio de inspeção sanitária, e análises laboratoriais. Completando o exposto, Lucchese(8) entende que se os instrumentos de vigilância sanitária não forem devidamente eficazes, podem ser gerados mais problemas, ao invés de resolvê-los, caso os produtos colocados no mercado tenham sua qualidade, segurança e eficácia questionáveis.

\section{O PROCESSO DE CONCESSÃO DE REGISTRO DE MEDICAMENTOS NA AGÊNCIA NACIONAL DE VIGILÂNCIA SANITÁRIA}

A Lei n. 9.782/99 implementou o Sistema Nacional de Vigilância Sanitária e criou a ANVISA. A agência foi instituída como uma autarquia especial,

(6) SAID, Dulcelina Mara Pereira. O registro sanitário de medicamentos: uma experiência de revisão. Rio de Janeiro: INCQS/Fiocruz, 2004. p. 156. Dissertação (Mestrado) - PPGVS, Rio de Janeiro, 2004.

(7) Boas Práticas de Fabricação para Medicamentos (BPF) são definidas pela Resolução RDC $n$. 210/03, que determina a todos os estabelecimentos fabricantes de medicamentos, o cumprimento das diretrizes estabelecidas no Regulamento Técnico das Boas Práticas para a Fabricação de Medicamentos, conforme o anexo I desta resolução, como sendo uma "parte da Garantia da Qualidade que assegura que os produtos são consistentemente produzidos e controlados", tendo como objetivo "primeiramente à diminuição dos riscos inerentes a qualquer produção farmacêutica, os quais não podem ser detectados através da realização de ensaios nos produtos terminados. Os riscos são constituídos essencialmente por: contaminação-cruzada, contaminação por partículas e troca ou mistura de produto."

(8) LUCCHESE, Geraldo. Globalização e regulação sanitária: os rumos da vigilância sanitária no Brasil. Rio de Janeiro: ENSP/Fiocruz, 2001. p. 228. Tese (Doutorado) - Saúde Pública, Rio de Janeiro, 2001. 
tendo como características a independência administrativa, a estabilidade de dirigentes e a autonomia financeira. Sua finalidade institucional, conforme o art. 60 da supracitada lei é:

Promover a proteção da saúde da população, por intermédio do controle sanitário da produção e da comercialização de produtos e serviços submetidos à vigilância sanitária, inclusive dos ambientes, dos processos, dos insumos e das tecnologias a eles relacionados, bem como o controle de portos, aeroportos e de fronteiras. ${ }^{(9)}$

Dentre as competências da ANVISA está a de conceder registros de produtos, segundo as normas de sua área de atuação. O ato de registro de produtos pode ser objeto de regulamentação, que vise à desburocratização e a agilidade nos procedimentos, desde que isto não implique riscos à saúde da população ou à condição de fiscalização das atividades de produção e circulação. ${ }^{(10)}$

Como definição de registro, a Lei n. 6.360/76, que dispõe sobre a vigilância sanitária a que ficam sujeitos os medicamentos, as drogas, os insumos farmacêuticos e correlatos, os cosméticos, saneantes e outros produtos, dispõe:

Inscrição, em livro próprio após o despacho concessivo do dirigente do órgão do Ministério da Saúde, sob número de ordem, dos produtos de que trata esta Lei, com a indicação do nome, fabricante, da procedência, finalidade e dos outros elementos que os caracterizem, ${ }^{(11)}$

O Decreto n. 79.094/77, que regulamenta a Lei n. 6.360/76, traz definições mais detalhadas para registro de produto, e registro de medicamento em seu art. 3ㅇ.

Registro de Produto - Ato privativo do órgão ou entidade competente do Ministério da Saúde, após avaliação e despacho concessivo de seu dirigente, destinado a comprovar o direito de fabricação e de importação de produto submetido ao regime da Lei n. 6.360, de 1976, com a indicação do nome, do fabricante, da procedência, da finalidade e dos outros elementos que o caracterize;

Registro de Medicamento - Instrumento por meio do qual o Ministério da Saúde, no uso de sua atribuição específica, determina a inscrição prévia no órgão ou na entidade competente, pela avaliação do cumprimento de caráter jurídico-administrativo e técnico-científico relacionada com a eficácia, segurança e qualidade destes produtos, para sua introdução no mercado e sua comercialização ou consumo;(12)

(9) BRASIL. Lei n. 9.782, de 26 de janeiro de 1999. Artigo 6․․ Disponível em: <http://www.anvisa.gov.br/ e-legis/>.

(10) BRASIL, artigo $7^{\circ}$, IX e artigo 41.

(11) BRASIL. Lei n. 6.360, de 23 de setembro de 1976. Disponível em: <http://www.anvisa.gov.br/ e-legis/>.

(12) BRASIL. Decreto n. 79.094, de 05 de janeiro de 1977. Artigo 3ํ․ Disponível em: <http:// www.anvisa.gov.br/e-legis/>. 
As exigências legais que devem ser seguidas pelas empresas a fim de que seja concedido o registro de medicamentos estão expostas no Decreto n. $79.094 / 77^{(13)}$, sendo estas mais específicas nas resoluções emitidas para cada categoria de medicamento pela ANVISA, ou mesmo em outras normas que são guias para a análise de questões que abrangem, tecnicamente, mais de uma categoria. Sendo o medicamento um produto especial, Said(14) ressalta que são necessárias etapas e conhecimentos multidisciplinares, como, por exemplo, a farmacologia e farmacotécnica, para o seu desenvolvimento. Da mesma maneira que são necessários determinados conhecimentos técnicos para o desenvolvimento dos medicamentos, estes também são essenciais no processo de registro. A fim de se entender esta complexidade da análise das petições, a seguir serão destacadas algumas exigências legais:

a. Detalhes da fabricação;

b. Comprovação de atendimento às normas reconhecidas pela Farmacopeia;

c. Provas de estabilidade e seus resultados;

d. Resultados das provas farmacológicas e toxicológicas em animais e os métodos utilizados;

e. Resultados dos testes de biodisponibilidade em casos necessários;

f. Resultados dos estudos em seres humanos;

g. Informações disponíveis sobre os efeitos adversos;

h. Cópias dos rótulos e bulas sobre medicamentos. ${ }^{(15)}$

Algumas das resoluções que abrangem mais de uma categoria de medicamentos são: Resolução RE n. 899/03(16), apresenta o guia para validação de métodos analíticos e bioanalíticos; Resolução RDC n. 333/03 ${ }^{(17)}$, dispõe sobre rotulagem de medicamentos; Resolução RDC n. 140/03(18), estabelece regras das bulas de medicamentos para pacientes e para profissionais de saúde; Resolução RDC n. 137/03(19), autoriza o registro e renovação de registro de medicamentos pertencentes a determinadas classes ou princípios ativos, apenas se as bulas e embalagens contiverem a advertência pertinente; Resolução RDC n. 138/03(20), dispõe sobre o enquadramento na categoria de venda - com ou sem prescrição médica - de medicamen-

(13) Id. Decreto n. 79.094, de 05 de janeiro de 1977, cit.

(14) SAID, Dulcelina Mara Pereira. op. cit.

(15) Id. Ibid., p. 44.

(16) Resolução RE n. 899, de 29 de maio de 2003.

(17) Resolução RDC n. 333, de 19 de novembro de 2003.

(18) Resolução RDC n. 140, de 29 de maio de 2003.

(19) Resolução RDC n. 137, de 29 de maio de 2003.

(20) Resolução RDC n. 138, de 29 de maio de 2003. 
tos; Resolução RE n. 310/04(21), apresenta o guia para realização do estudo de equivalência farmacêutica e perfil de dissolução (aplicando-se para os medicamentos genéricos e similares que têm que ser equivalentes ao medicamento de referência); Resolução RE n. 01/05(22), apresenta o guia para a realização de estudos de estabilidade. ${ }^{(23)}$

É possível identificar a complexidade que envolve a análise de documentação para registro de medicamentos apenas por observar a quantidade de assuntos envolvidos nos regulamentos, que devem ser cumpridos pelas empresas solicitantes, para que seja deferida a petição de registro de medicamentos. A análise, portanto, requer muito conhecimento técnico e tem como finalidade principal fornecer à população medicamentos com qualidade, segurança e eficácia.

Comparando-se o processo de registro de medicamentos atual, com o efetuado pelos órgãos competentes anteriores à ANVISA, em ordem cronológica a Secretaria Nacional de Vigilância Sanitária e Secretaria de Vigilância Sanitária, pode-se perceber que hoje existe uma preocupação maior com esta análise técnica, pois antes o registro era considerado apenas um ato cartorial. Esta caracterização:

(...) comprometia a qualidade e a eficácia do registro sanitário (...) o que gerava a desconfiança quanto à eficácia da Visa federal e a qualidade dos medicamentos existentes no mercado. ${ }^{(24)}$

(...) os instrumentos técnico-científicos utilizados pelos profissionais para pautar suas análises praticamente inexistiam, o que acarretava uma análise praticamente comparativa com um processo de registro já concedido ou informações constantes de publicações não científicas. ${ }^{(25)}$

Mesmo com um maior rigor nas análises, em razão do cumprimento das resoluções, deve-se ressaltar que o procedimento administrativo desta análise não é especificado na legislação, o que acarreta, muitas vezes, o uso da discricionariedade técnica para decisões a serem tomadas pelo agente administrativo que analisa as petições de registro. Neste momento faz-se necessário o esclarecimento quanto ao conceito de processo e procedimento utilizados neste trabalho. Para Dias ${ }^{(26)}$ processo é: a "série de atos preparatórios de uma decisão final da Administração." Esta decisão, ou ato final, é "sempre precedido de uma série de atos (...) consistentes em estudos, pare-

(21) Resolução RE n. 310, de 01 de setembro de 2004.

(22) Resolução RE n. 01, de 29 de julho de 2005.

(23) Para maiores esclarecimentos com relação ao conteúdo das resoluções, recomenda-se a consulta das referências legais, uma vez que apresentam temas diversos e específicos, cada um com uma finalidade, abrangendo informações para a garantia de que o medicamento analisado é seguro, eficaz e de qualidade.

(24) SAID, Dulcelina Mara Pereira. op. cit., p. 61.

(25) Id. Ibid., p. 66.

(26) DIAS, Hélio Pereira. Flagrantes do ordenamento jurídico-sanitário. 2. ed. Brasília: ANVISA, 2004. p. 303. 
ceres, informações, laudos (...)", ou seja, o necessário para fundamentá-lo. Ainda segundo o autor, não se deve confundir processo com procedimento, uma vez que o último se desenvolve dentro de um processo administrativo, equivalendo à forma de proceder.

Para citar um exemplo de determinação legal que pode ser interpretada, pode-se observar o descrito no Decreto n. 79.094/77 e na Lei n. 6.360/76 quanto à rotulagem e publicidade de medicamentos. É determinado que não devem constar da rotulagem dos medicamentos:

(...) designações, nomes geográficos, símbolos, figuras, desenhos ou quaisquer indicações que possibilitem interpretação falsa, erro ou confusão quanto à origem, procedência, natureza, composição ou qualidade, que atribuam ao produto finalidades ou características diferentes daquelas que realmente possua. ${ }^{(27)}$

Porém, o que pode ser considerado como símbolo inócuo para a empresa, que deseja destacar o seu produto com relação aos concorrentes, pode não o ser no entendimento do técnico que analisa a embalagem do produto. Um desenho pode ser classificado como um causador de confusão para o consumidor, ou ainda um incentivo ao uso de medicamentos, que devem ter o uso de forma racional. Mas este entendimento por parte do corpo técnico pode não ser unânime, gerando diferentes posicionamentos da administração.

Um outro exemplo pode ser citado considerando-se a questão da responsabilidade da análise. Se um medicamento genérico entra no mercado em que somente existia o medicamento de referência, há possibilidade de um maior número de pessoas terem acesso ao tratamento ${ }^{(28)}$. Quem torna isto possível é o agente público responsável pela análise da documentação enviada na petição do registro. Porém, se este medicamento é disponibilizado no mercado com uma qualidade, segurança ou eficácia duvidosa, da mesma maneira é causado um impacto, agora negativo, para a população.

\section{PRINCÍPIOS ADMINISTRATIVOS NO ÂMBITO DO REGISTRO DE MEDICAMENTOS}

A Constituição Federal de 1988, no caput do art. 37, norteia a administração pública, direta e indireta, com os princípios de legalidade, impessoalidade, moralidade, publicidade e eficiência. ${ }^{(29)}$ A Lei n. 9.784/99, que regula o processo administrativo no âmbito da Administração Pública Federal, no

(27) BRASIL. Lei n. 6.360, de 23 de setembro de 1976, cit., art. 59.

(28) Conforme o artigo 12 da Resolução n. 02, de 05 de março de 2004 o preço do medicamento genérico não pode ser superior a $65 \%$ do preço do seu medicamento de referência.

(29) Constituição da República Federativa do Brasil, 1988, art. 37, caput. 
caput do art. 2을 especifica que a administração pública deve obedecer aos princípios da legalidade, finalidade, motivação, razoabilidade, proporcionalidade, moralidade, ampla defesa, contraditório, segurança jurídica, interesse público e eficiência, dentre outros. ${ }^{(30)}$

A ANVISA, sendo uma autarquia da administração pública indireta deve, portanto, observar em seus atos tais princípios administrativos, pois se praticados sem sua observância podem perder a validade. Pode-se dizer então que o ato administrativo do registro de medicamentos deve: seguir a legislação vigente; ser impessoal e moral, ter a finalidade de atender aos interesses da coletividade com a oferta de medicamentos com segurança, eficácia e qualidade no mercado; tornar-se público, o que ocorre por meio da publicação do deferimento ou indeferimento da solicitação do registro, em Diário Oficial da União (DOU), também havendo a divulgação dos registros concedidos na página eletrônica da ANVISA; e eficiente, dando a melhor resposta para determinado processo, de forma mais rápida possível.

Ainda que justificada pelo órgão competente, a demora para a primeira manifestação ao solicitante além do prazo definido na lei vai contra os princípios da legalidade e da eficiência. Este argumento pode ser utilizado em mandados judiciais para a obtenção do registro, porém, neste caso o princípio da supremacia do interesse público tem grande importância. Em um exemplo de jurisprudência, a decisão foi "no sentido de não conceder o registro pedido pelo impetrante"(31) considerando a supremacia do interesse público, ao prezar a saúde coletiva confrontada ao interesse da empresa:

O pedido, no caso, foi expresso, para que se determinasse o imediato registro dos produtos, impossível de ser atendido, sem a indispensável análise técnica, até porque sujeitaria o público, o consumidor, a eventuais riscos à sua saúde. ${ }^{(32)}$

\section{ATOS ADMINISTRATIVOS E O GRAU DE LIBERDADE NA SUA PRÁTICA}

Pode-se dizer que ato administrativo é a manifestação do exercício da função administrativa para a obtenção do interesse público, que tem como objetivo a aquisição, conservação, transformação, transmissão e extinção de direitos. Segundo Meirelles ${ }^{(33)}$ :

(30) BRASIL. Lei n. 9.784, de 29 de janeiro de 1999. Art. 2o, caput. Disponível em: <http:// www.anvisa.gov.br/e-legis/>.

(31)HORTA, Marcelo Palis. Aspectos formais sobre o registro de medicamentos e os limites da atuação judicial. Revista de Direito Sanitário, São Paulo, v. 3, n. 3, p. 66, nov. 2002.

(32) Id. Ibid., p. 66, grifo nosso.

(33) MEIRELLES, Hely Lopes. Direito administrativo brasileiro. Atualizado por Eurico A. Azevedo et al. 6. ed. São Paulo: Malheiros, 2001. 
Ato administrativo é toda manifestação unilateral de vontade da Administração Pública que, agindo nessa qualidade, tenha por fim imediato adquirir, resguardar, transferir, modificar, extinguir e declarar direitos, ou impor obrigações aos administrados ou a si própria.

Existem cinco elementos necessários para que qualquer ato seja considerado válido. O art. $2^{\circ}$ da Lei n. 4.717/65 dispõe que são nulos os atos nos casos de incompetência, vício de forma, ilegalidade do objeto, inexistência dos motivos, desvio de finalidade. ${ }^{(34)}$ Assim, conclui-se que o ato administrativo tem como elementos básicos: competência, forma, objeto, motivo e finalidade.

Para Di Pietro(35), quando a lei não deixa opções para o administrador, preenchendo os muitos aspectos de determinada atividade, ou seja, diante de determinados requisitos a administração só pode agir de formas especificadas, diz-se que o poder da administração é vinculado. Portanto, no ato administrativo vinculado, a lei enumera os cinco elementos legais, não existindo nenhum juízo de valor por parte do agente público. Quando a lei deixa que o agente público opte por uma solução dentre as possíveis em determinado caso, diz-se que a administração exerce o poder discricionário, pois sua decisão ocorre utilizando-se de mérito administrativo "segundo critérios de oportunidade, conveniência, justiça, equidade, próprios da autoridade porque não definidos pelo legislador."(36). Esta noção de discricionariedade ocorre devido à impossibilidade de serem previstas nas leis todas as hipóteses de fato e suas soluções mais coerentes para cada caso. ${ }^{(37)}$ Porém, mesmo configurando ato discricionário, este não é totalmente livre, pois os elementos - competência, finalidade e forma - são sempre vinculados, portanto existindo limitações na lei, que se ultrapassadas a decisão da administração passa a ser contrária à lei, arbitrária.

Mello(38) conceitua discricionariedade da seguinte forma:

Discricionariedade é a margem de "liberdade" que remanesça ao administrador para eleger, segundo critérios consistentes de razoabilidade, um, dentre pelo menos dois comportamentos, cabíveis perante cada caso concreto, a fim de cumprir o dever de adotar a solução mais adequada à satisfação da finalidade legal, quando, por força da fluidez

(34) BRASIL. Lei n. 4.717, de 29 de junho de 1965. Artigo 2o․ Disponível em: <http://www.planalto.gov.br/ ccivil/LEIS/L4717.htm>.

(35) DI PIETRO, Maria Sylvia Zanella. Direito administrativo. 15. ed. São Paulo: Atlas, 2003.

(36) Id. Ibid., p. 205.

(37) DI PIETRO, Maria Sylvia Zanella. Discricionariedade administrativa na Constituição de 1988. São Paulo: Atlas, 1991 apud MACEDO, Jaqueline Mainel Rocha de. Discricionariedade técnica e função normativa em setores regulados, e sua identificação na lei geral de telecomunicações. In: ARANHA, M.I. (Org.). Direito das telecomunicações: estrutura institucional regulatória e infraestrutura das telecomunicações no Brasil. Brasília: GETEL; Faculdade de Direito; UnB, 2005. p. 121-185. (38) MELLO, Celso Antônio Bandeira de. Curso de direito administrativo. 21. ed. São Paulo: Malheiros Ed., 2006. p. 926. 
das expressões da lei ou da liberdade conferida no mandamento, dela não se possa extrair objetivamente uma solução unívoca para a situação vertente.

\section{Discricionariedade técnica}

Alessi(39) coloca uma distinção entre a discricionariedade administrativa e a discricionariedade técnica. É explicitado que "enquanto a primeira é observada nos casos em que a apreciação do interesse público diz respeito à utilização exclusiva de critérios administrativos (...)", a discricionariedade técnica é verificada “(...) na existência e solução de questões técnicas para apreciação do interesse público, posterior ou concomitantemente".

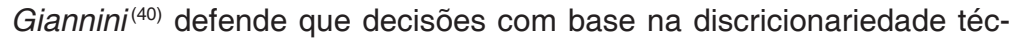
nica devem ser motivadas, também tecnicamente, afastando assim "o arbítrio, o erro, a impostura e a irrazoabilidade", sendo o último relativo a afastar decisões "desnecessárias, inadequadas e desproporcionais". O autor ainda esclarece que:

(...) nos casos em que a lei prescreve à Administração uma atividade de aclaramento da realidade tecnicamente complexa que importa no emprego de disciplinas especializadas, ou mesmo nos casos em que esse aclaramento for necessário ao exercício do poder, esta doutrina (criticável, porém consolidada) considera atribuído um verdadeiro e adequado poder discricionário (de conteúdo técnico).

Em razão do exposto, o conteúdo válido das normas baixadas pelas agências reguladoras, das quais a de vigilância sanitária é um adequado exemplo, está integralmente definido na margem de escolha técnico-científica que a legislação delegante abriu à exclusiva discrição dos respectivos agentes técnicos.

Macedo(41) classifica "a discricionariedade técnica como espécie do gênero discricionariedade administrativa" e diz que essa discricionariedade "participa no ordenamento jurídico como meio para concretização do teor abstrato contido nas normas de grau hierárquico mais elevado". Conclui também que:

Pela análise dos mecanismos geradores da discricionariedade nas leis, chegou-se a conclusão de que a inserção de conceitos jurídicos indeterminados é um dos grandes responsáveis pela fixação de margens

(39) Cf. ALESSI, Renato. Instituciones de derecho administrativo - tomo I, Barcelona: Bosch Casa Editorial, 1970, p. 196. apud MACEDO, Jaqueline Mainel Rocha de. op. cit., p. 138.

(40) GIANNINI, Massimo Severo. Diritto amministrativo. 3.ed. Milano: Giuffrè, 1993. v.1, apud DIAS, Hélio Pereira. op. cit., p. 85.

(41) MACEDO, Jaqueline Mainel Rocha de. op. cit., p. 184. 
de volição, e não apenas de intelecção na norma. Desse modo, são eles aptos, sim, a gerar, no bojo da lei, uma margem de escolha a ser exercida pelas agências reguladoras, principalmente, no momento da edição de atos normativos.

Pode-se dizer que o assunto da discricionariedade técnica mostra-se com maior destaque com a criação das agências reguladoras, como a ANVISA. Este conceito ainda deve ser mais discutido, pois, sua classificação como espécie da discricionariedade administrativa pode causar confusão, principalmente nos atos como o registro de produtos, em que classicamente é considerado como ato vinculado da administração.

\section{2. $O$ ato administrativo no âmbito do registro de medicamentos}

Com relação à natureza jurídica do registro sanitário, Dias transcreve matéria do Jornal Valor Econômico, edição de 26 de janeiro de 2004, que traz um estudo da Procuradoria da ANVISA, fazendo explicações quanto ao registro de medicamentos e a Lei n. 6.360/76:

A supramencionada lei estabelece, outrossim, os requisitos e condições necessárias à concessão do registro de medicamentos. Trata-se, pois, de ato vinculado e regrado que vigora pelo prazo fixado em lei para sua validade, se e quando o seu titular mantiver as características do produto quanto à sua identidade, atividade, qualidade, pureza e inocuidade necessárias. (...)

(...) porque apresentando a natureza jurídica de ato administrativo vinculado, o registro é concedido em caráter personalíssimo ao fabricante que preencha todos os requisitos estabelecidos pela lei; 3) porque o registro é informado pelos princípios e normas de direito público, não podendo os institutos de direito privado serem aplicados unilateralmente pelo particular no tocante a pretensos atos de alienação do registro de medicamentos, sob pena de se macular o princípio da legalidade e o princípio da indisponibilidade dos bens e interesses públicos (...) $)^{(42)}$

Horta $^{(43)}$ dispõe os elementos do ato administrativo no registro de medicamentos, também o caracterizando como ato vinculado. Segundo o autor, no ato do registro de medicamentos: o objeto é a concessão de registro; o motivo decorre da averiguação quanto à conformidade de todas as exigências legais e, se estiverem adequadas na petição, o registro deve ser concedido; a forma é escrita, sendo a decisão da administração publicada no DOU e a finalidade é o interesse público a ser atingido.

(42) DIAS, Hélio Pereira. op. cit., p. 181, original com grifos.

(43) HORTA, Marcelo Palis. op. cit. 
Quanto ao objeto pode-se ampliar o entendimento para o registro de medicamentos como sendo: a concessão, dada pelo deferimento da petição que foi submetida à análise técnica, ou a não concessão, resultando a análise em indeferimento do pleito. De acordo com o inciso IX do art. $7^{\circ}$ da Lei $n$. 9.782/99, a competência de "conceder registros de produtos, segundo as normas de sua área de atuação" é atribuída à ANVISA. ${ }^{(4)}$

É possível levantar a discussão sobre o tipo de ato administrativo exercido como resultado da análise das petições de registro. Mesmo caracterizando-se o ato como vinculado, uma vez que existem critérios estritos a serem seguidos, também existe margem para a discricionariedade técnica, pois os procedimentos, que compõem o processo, a serem seguidos pela administração, não estão sempre estabelecidos em lei. Com relação a essa discussão, ao falar sobre a Lei n. 6.360/76(45), Said(46) descreve:

Essa Lei define registro para produto, licença para o estabelecimento e a autorização para funcionamento da empresa. Em se tratando de ato discricionário, o cancelamento do registro poderá ocorrer sempre que o interesse público assim o exigir, à vista de razões fundamentadas.

Estendendo o exposto pela autora, percebe-se que pode haver um entendimento quanto à discricionariedade, também no ato do registro de medicamentos.

O processo de registro é precedido de atos, como pareceres técnicos, em que normalmente se fundamenta o deferimento ou indeferimento da petição à pessoa jurídica solicitante. Porém, a fiel observância das resoluções, que funcionam como guias possuindo cunho técnico, depende do conhecimento do servidor público que analisa a petição. Neste contexto, percebe-se a necessidade de minimizar a possível variedade de entendimentos, por intermédio de capacitação dos funcionários que analisam as petições de registro, entendendo que para o tema saúde, e sendo o registro um ato vinculado, divergências não devem ser usuais.

\section{CONSIDERAÇÕES FINAIS}

O medicamento, por ser um produto especial, tem que apresentar critérios de eficácia, segurança e qualidade, com a finalidade de detectar a existência de possíveis riscos à saúde pública e minimizar os seus efeitos por meio de análise

(44) BRASIL. Lei n. 9.782, de 26 de janeiro de 1999, cit.

(45) Os artigos 6ㅇ e $7^{\circ}$ da Lei n. 6.360, de 23 de setembro de 1976 ditam a possibilidade de cancelamento do registro, apreensão, suspensão da fabricação e venda, de qualquer dos produtos de que trata esta lei, que, embora registrado, se torne suspeito de ter efeitos nocivos à saúde humana.

(46) SAID, Dulcelina Mara Pereira. op. cit., p. 46. 
rigorosa das petições de registro. $\mathrm{Na}$ análise complexa e multidisciplinar do processo de registro de medicamentos, foi destacado o componente técnico, não sendo o registro um ato meramente cartorial. Para que o ato seja válido, considerou-se ainda a necessidade de serem seguidos os princípios da administração pública. Foi percebida também a importância de os agentes administrativos envolvidos na análise técnica de registro terem consciência do impacto para a população, negativo ou positivo, decorrente da entrada de medicamentos no mercado farmacêutico.

Apesar do ato administrativo do registro de medicamentos ser caracterizado, do ponto de vista jurídico, como ato vinculado, uma vez que os cinco elementos do ato são enumerados em lei, este é um tema ainda não muito claro, principalmente para os que não têm formação na área do direito, como os agentes públicos apreciadores do pedido de registro. Apesar de haver na atualidade maior detalhamento de normas em relação a períodos passados, a forma de proceder à análise não é descrita na legislação, cabendo a aplicação da discricionariedade técnica.

O termo discricionariedade técnica não deve ser confundido com subjetividade, devendo a administração estar bem fundamentada tecnicamente, para tomar a correta decisão, no caso, permitir ou não o registro a determinado medicamento. Nesse sentido, sugere-se: (1) que haja permanente capacitação dos técnicos que atuam na análise de documentação nas petições de registro de medicamentos, a fim de mantê-los atualizados quanto às tecnologias do ramo farmacêutico; (2) a criação de mecanismos de visualização dos resultados do trabalho técnico; (3) reavaliar o processo de registro em termos dos procedimentos adotados, com o objetivo de minimizar os possíveis riscos à saúde do consumidor.

\section{REFERÊNCIAS BIBLIOGRÁFICAS}

BRASIL. ANVISA. Resolução n. 02, de 05 de março de 2004. Disponível em: <http://www.anvisa.gov.br/e-legis/>.

ANVISA. Resolução RDC n. 140, de 29 de maio de 2003. Disponível em: <http://www.anvisa.gov.br/e-legis/>.

. ANVISA. Resolução RDC n. 137, de 29 de maio de 2003. Disponível em: <http://www.anvisa.gov.br/e-legis/>.

. ANVISA. Resolução RDC n. 138, de 29 de maio de 2003. Disponível em: <http://www.anvisa.gov.br/e-legis/>.

ANVISA. Resolução RDC n. 210, de 04 de agosto de 2003. Disponível em: <http://www.anvisa.gov.br/e-legis/>.

ANVISA. Resolução RDC n. 333, de 19 de novembro de 2003. Disponível em: <http://www.anvisa.gov.br/e-legis/>. 
ANVISA. Resolução RE n. 899, de 29 de maio de 2003. Disponível em: <http://www.anvisa.gov.br/e-legis/>.

. ANVISA. Resolução RE n. 310, de 01 de setembro de 2004. Disponível em: <http://www.anvisa.gov.br/e-legis/>.

ANVISA. Resolução RE n. 01, de 29 de julho de 2005. Disponível em: <http://www.anvisa.gov.br/e-legis/>.

Constituição da República Federativa do Brasil, 1988. Disponível em: <http://www.planalto.gov.br/CCIVIL_03/Constituicao/Constitui\%C3\%A7ao.htm>.

. Decreto n. 79.094, de 05 de janeiro de 1977. Disponível em: <http:/ /www.anvisa.gov.br/e-legis/>.

. Decreto n. 74.170, de 10 de junho de 1974. Disponível em: <http:// www.anvisa.gov.br/e-legis/>.

. Decreto n. 79.094, de 05 de janeiro de 1977. Disponível em: <http:/ /www.anvisa.gov.br/e-legis/>.

. Lei n. 4.717, de 29 de junho de 1965. Disponível em: <http:// www.planalto.gov.br/ccivil/LEIS/L4717.htm>.

. Lei n. 5.991, de 17 de dezembro de 1973. Disponível em: <http:// www.anvisa.gov.br/e-legis/>.

. Lei n. 6.360 , de 23 de setembro de 1976. Disponível em: <http:// www.anvisa.gov.br/e-legis/>.

. Lei n. 8.080, de 19 de setembro de 1990. Disponível em: <http:// www.anvisa.gov.br/e-legis/>.

. Lei n. 9.782, de 26 de janeiro de 1999. Disponível em: <http:// www.anvisa.gov.br/e-legis/>.

Lei n. 9.784, de 29 de janeiro de 1999. Disponível em: <http:// www.anvisa.gov.br/e-legis/>.

DI PIETRO, Maria Sylvia Zanella. Direito administrativo. 15. ed. São Paulo: Atlas, 2003.

DIAS, Hélio Pereira. Flagrantes do ordenamento jurídico-sanitário. 2. ed. Brasília: ANVISA, 2004.

HORTA, Marcelo Palis. Aspectos formais sobre o registro de medicamentos e os limites da atuação judicial. Revista de Direito Sanitário, São Paulo, v. 3, n. 3, p. 52-68, nov. 2002.

LUCCHESE, Geraldo. Globalização e regulação sanitária: os rumos da vigilância sanitária no Brasil. Rio de Janeiro: ENSP/Fiocruz. 2001. Tese (Doutorado) - Saúde Pública, Rio de Janeiro, 2001.

MACEDO, Jaqueline Mainel Rocha de. Discricionariedade técnica e função normativa em setores regulados, e sua identificação na lei geral de telecomunicações. In: ARANHA, M.I. (Org.). Direito das telecomunicações: estrutu- 
ra institucional regulatória e infraestrutura das telecomunicações no Brasil. Brasília: GETEL; Faculdade de Direito; UnB, 2005. p. 121-185.

MEIRELLES, Hely Lopes. Direito administrativo brasileiro. Atualizado por: Eurico A. Azevedo et al. 6. ed. São Paulo: Malheiros Ed., 2001.

MELLO, Celso Antônio Bandeira de. Curso de direito administrativo. 21. ed. São Paulo: Malheiros Ed., 2006.

SAID, Dulcelina Mara Pereira. O registro sanitário de medicamentos: uma experiência de revisão. Rio de Janeiro: INCQS/Fiocruz, 2004. Dissertação (Mestrado) - PPGVS, Rio de Janeiro, 2004.

SANTOS, Denise Lyra dos. $O$ ato administrativo de concessão de registro de medicamentos na agência nacional de vigilância sanitária. Brasília: Direb; Fiocruz. 2007. Monografia (Especialização) — Direito Sanitário, Brasília, 2007. 